\title{
On the Information Selection of Scientific and Technical Communication ${ }^{\dagger}$
}

\author{
Jian Lin \\ Renmin University of China, Beijing 100872, China; linj3551@sina.com; Tel: +86-186-0054-5655 \\ + Presented at the IS4SI 2017 Summit DIGITALISATION FOR A SUSTAINABLE SOCIETY, Gothenburg, \\ Sweden, 12-16 June 2017.
}

Published: 9 June 2017

\begin{abstract}
This dissertation studies the problem of information selection of scientific and technical communication. In this thesis I analyze the characteristic, essence, element, structure, function, effect and obstruct in scientific and technical communication, discuss the process, mechanism, principle, method and the way of information selection. I also seek the value of achievements in scientific research and technological development, analyze its evaluation and transformation, and explore the interaction between science-technology and society. I discuss the selective problem of scientific and technical education, scientific and technical popularization. In the process of globalization, there exists unbalanced information communication. At last, I discuss the relation between scientifictechnical communication and international competition power. I put forward a proposal for building up an effective network of scientific and technical communication, which is very significant to the national innovation systems and social development. The main conclusions are: (1) scientific and technical communication is the bridge connecting science-technology and society. The communication process is a nonlinear dynamic system in which many elements interact; (2) In order for an effective application, it's necessary that the communication be all-round based on the need and appropriate selection, not only the information and knowledge of science \& technology, but also the scientific method, spirit, civilization be communicated. In the meantime, the social problems need to be taken care of; (3) All individuals, communication media, education and research institutions, corporations, as well as the entire country need to take some proper steps according to the situation for effective selections; (4) During the process of establishing the national innovation systems, carrying out the strategy of sustained development and rejuvenating China through science and education, we must enhance scientific \& technical communication and pay special attention to information selection.
\end{abstract}

Part 1: Analysis for the system of scientific and technological communication Scientific and technical communication is one of communication behaviors of human, which was born when human civilization developed to certain extent. As a component of science and technology, it is called "blood circulation systems" of science-technology and society, which are the lifelines of economy and society. In the middle of the 20th century, the information and biology revolution marked the revolution of the modern science and technology. Meanwhile, there have emerged a lot of new features in the scientific and technological communication. Scientific and technological communication is one form of information communication, whose activities include scientific and technological writing, publishing, news, education, popularization, translation, information exchange, consultation, library, exhibition, museums, data base, etc. Knowledge and information of science and technology, through time and space crossover diffusion, realizes knowledge sharing among different individuals, transforms private knowledge into society-sharing knowledge. Instead of a combination of various methods and channels, system of scientific and technical communication is a unified organism, whose elements consist of communicator, content, media and receiver. They are interrelated and interacted, forming a structure of layered classes and gradations. The functions of scientific and technical communication include: (1) to stimulate knowledge 
transformation and development of science and technology; (2) to train science and technology professionals, enhance people's qualification of science and technology; (3) to accelerate the transformation of scientific and technological achievements, benefit the development of economy and society; (4) to strengthen international communication and cooperation, carry forward human civilization. It is hoped to get long-term, expected, and positive effects. We must pay special attention to the behaviors of stealing the name of science but actually doing non-science and even against-science. Also, we must look at the system of scientific and technological communication as a subsystem of the grand social system. There are obstacles in the communication process, so it becomes necessary to remove them, to get ride of useless information and to select effective information.

Part 2: The mechanism of information selection. The information is extremely rich in modern society. It assumes the tendency of "knowledge explosion" and "information sea", which give rise to serious interference in the communication process, such as unnecessary, out-of-date, antiquated, false, rubbish and filthy information, virus information, etc. So we must select effective and beneficial information. The process of information selection includes information collecting, receiving, handling, treating, storing, retrieving, spreading, etc. It requires to differentiate, classify, analyze, compute, sort, code, label and organize the information to make them increment, so as to acquire maximum economic and social effect. People's cognition, emotion and will, which relate to background of knowledge, interest, favor, habit and economic situation, etc., play an important role in the selecting process. The communicator and receiver follow different principles. Of that the communicator complies with the rules of being efficient, objective, systematic, directed, matching, standardized, safe, etc. while the receiver obeys the law of selection, which includes selectively receiving, selectively understanding, selectively memorizing and selectively practicing, selects the needed information using the minimum effort principle to. Besides usefulness, efficiency and effect, convenience, safety, being economical should also be considered. There are couple of ways of information selection, namely, independent selection and passive selection. There are also a lot of tools for information selection, e.g., newspaper, magazine, book, broadcast, television, data base, network, etc. Some institutes of information services provide services on science and technology, which makes the information service professional and industrialized.

Part 3: The valuation and selection of the achievements of science and technology. One of the most important objectives of scientific and technical communication is to communicate and spread the achievements of science and technology. Science and technology have value and use value, or theoretical value and practical value, e.g., objective value and implement value, as well as truth value, education value, culture value, etc. There are two kinds of valuations to science and technology, namely, the valuation from the scientific and technical community, and the valuation from the society. More precisely, valuation is shown in the publishing, differentiating, identifying, quoting, rewarding and encouraging, etc. The achievements of science and technology are communicated and spread through valuation and selection. As property right of knowledge about the achievements of science and technology gets protected, technological monopoly should also be avoided. The information about science and technology, reversely, affects the development of science \& technology. So it is necessary to select properly contents, not only the information and knowledge of science \& technology, but also the problems related to science-technology and society, in the communication process, and to face up with the challenge raised by post-modern science. In modern society, science \& technology and production form an entirety. Scientific research has benefited technological improvement, which drives economic development. The transformation of the achievements in science and technology involves in the process of commercialization and industrialization. So it is necessary to establish a channel between science-technology and society through scientific and technological communication.

Part 4: The scientific and technical education, popularization and public selection. The scientific and technical education is a necessary condition to put the system of science \& technology into 
permanent operation. It plays an important role in communicating the knowledge, method and spirit of science \& technology, and in training professionals. We must carry on the quality, intelligence, innovation and lifelong education. We need to combine the scientific and technological education with humanism education, recognize the science \& technology as a cultural process, pursue the unity of truthfulness, goodness and beauty. The scientific and technological popularization towards public, along with the mass media, is very important. It consists of news, publish, broadcast, television, data base, network, etc. The communication of science \& technology to the public via the mass media requires a modified approach to the traditional presumptive models of communicative style. Conventional models of scientific and technical communication are based on implicit but unexamined assumptions that the most effective and important means of transmission of scientific and technical information are efforts aimed at the attentive segments of the population through specialized and detailed formats. Based on the theory of uses and gratification approach, we should select properly. People's qualification of science \& technology in our country is poor, so we must take actions to promote. Attempts to reach inattentive audiences with scientific and technological information are customarily unsuccessful or have been deemed unnecessary altogether. The proposed model submits that not only are endeavors to communicate scientific ideas to the disinterested populace of overriding importance but can be quite successful if production styles are altered to reflect more "interest-motivating" designs. A new thrust toward capturing the attention of disinterested audiences before attempting to directly disseminate scientific ideas is proposed.

Part 5: The globalization and selection of scientific and technological information the flow of information makes the world become an "earth village". The organic whole trend of the globe is clear. There exists serious unbalanced state on international information communication, so as to some "rich information countries" and some "poverty information countries" emerge. Scientific and technical information and knowledge occupy important places in the global communication, in which culture plays a role as "filter" and "catalyst". There is a need to introduce some foreign scientific and technological books to our country. Based on our conditions, we should translate and introduce the reams of information technology, biology technology, energy technology, material technology, and synthetic, cross subjects, etc. Modern culture relates closely with science \& technology and education. There are many kinds of selections as tradition and background differ. We should maintain vigilance to the "culture imperialism" and avoid the "culture departmental selfishness". Scientific and technological communication relates closely with international competition power. On the times of knowledge-economy, national innovation systems are extremely important. The national innovation systems circle relations of production, consist of knowledge innovation, technological innovation, institutional innovation, managerial innovation, it is a kind of wholly synthesized innovation. The system of knowledge communication contains not only educational institution, but also the mass communication media. They are the same important on communication with production of knowledge. The system of knowledge communication acts as a bridge connecting knowledge innovation and knowledge application, also, it is the key factor of knowledge innovation and technological innovation. Establishing an effective network of scientific and technical communication is significant to the construction of national innovation systems, and to the realization of the strategy about rejuvenating China by science and education, and the strategy of sustained development, which is the sole correct selection.

Keywords: scientific and technical communication; system; information; selection 